\title{
LOS LEGIONARIOS DE CRISTO: RED PEDERASTA, PODER Y CORPORACIÓN EMPRESARIAL TRANSNACIONAL
}

\author{
THE LEGIONARIES OF CHRIST: PEDERAST NETWORK, POWER AND \\ TRANSNATIONAL BUSINESS CORPORATION
}

\author{
Ricardo Melgar B. ${ }^{1}$ \\ Instituto Nacional de Antropología e Historia de México \\ (RECIBIDO 05/06/2012, ACEPTADO 20/11/2012)
}

\begin{abstract}
RESUMEN
La dimensión global de la pederastia está asociada al turismo sexual, el negocio de la pornografía infantil y la pederastia eclesial, la cual ha conmocionado a las dos Américas, aunque sus redes transnacionales y de poder que le son inherentes hayan sido insuficientemente analizadas y debatidas. Realizaremos un estudio de caso de pederastia eclesial transnacional a través de la orden Legionarios de Cristo. Los orígenes de este poder fáctico y las perversiones que la significaron, se ubican entre la Segunda Guerra Mundial y los inicios de la Guerra Fría. Reintegramos a Marcial Maciel -su fundador- a sus redes de poder y complicidad en un arco temporal mayor hasta su punto de quiebre. Discutimos la trama real y simbólica de la pederastia eclesial a través de categorías y símbolos diversos: el poder, el dolor, la pureza, la mácula y las sustancias alteradoras de la conciencia y de los sentidos (opiáceas).
\end{abstract}

Palabras clave: pederastia, Legionarios de Cristo, dolor, pureza, poder, redes.

\begin{abstract}
The global dimension of pederasty is associated with sexual tourism, the business of child pornography and ecclesial pederasty, which has shocked the two Americas, although their transnational networks and power which are inherent have been insufficiently analyzed and discussed. We will make a case study of transnational ecclesial pederasty through the Legionaries of Christ order. The origins of this factual power and the perversions that meant, are among World War II and the beginnings of Cold War. We restore Marcial Maciel- its founder- to their power networks and complicity in a greater time span until breaking point. We discussed the real and symbolic weft of pederasty ecclesial through various categories and symbols: power, pain, purity, macula and the consciousness-altering substances (opiates).
\end{abstract}

Keywords: pederasty, Legionaries of Christ, pain, purity, power, networks.

1 Investigador de tiempo completo del Instituto Nacional de Antropología e Historia (México). E-mail: trmelgarbao@gmail.com. 


\section{INTRODUCCIÓN}

Ha sido de dominio público global que los Estados Unidos han sacado a luz que la pederastia es una práctica muy extendida en las instituciones católicas por la que se han hecho merecedoras de sanciones, mientras que en América Latina, un continente mayoritariamente católico, dicho asunto no terminará de tocar fondo, mientras se insista en que se tratan de casos aislados. El estigma anticlerical -otrora escudo defensivo eclesial- ha perdido eficacia simbólica para escamotear el derecho de las víctimas a la reparación y a la sanción de sus victimarios, o para descalificar a los estudios académicos o investigaciones periodísticas que dan cuenta de ella. El Vaticano yerra al subsumir la pederastia dentro de la homosexualidad y yerra también al desvincularla de los lastres del celibato. La ausencia de una reforma en el Derecho Canónico y en los tribunales eclesiásticos es preocupante, considerando que la sanción mayor para un cura pederasta es la de la "renuncia al estado clerical." (Amenós y Martínez, 2007). Pero cuando, estos actos se sitúan en las alturas de la jerarquía eclesial quedan solapados y tratados con fino cuidado. La invitación al retiro espiritual de Maciel realizada por el papa Juan Pablo II y avalada por Ratzinger dice mucho al respecto.

La historia de la pederastia en América Latina es casi inexistente, salvo una fragmentaria casuística, que ha oscilado entre marcos interpretativos dominantemente positivistas o empiristas. En ella la pederastia eclesial se ha vuelto un tema emergente. Nuevos aires en torno a su estudio se avizoran en los espacios académicos, aunque todavía no puedan superar los legados de las narrativas anticlericales que han competido con los discursos moralistas sobre la cuestión pederasta. En el ámbito conceptual, la pederastia posee una complicada y polémica genealogía de sentido que cubre un arco temporal que se inicia a mediados del siglo XIX al presente, marcada por los embates de la modernidad y sus modas replicantes. Su sentido fuerte radica en el ejercicio de la violencia sexual contra un menor de edad. Los primeros estudios sobre la pederastia en el siglo XIX subrayaron el hecho de que siendo sus manifestaciones bastante frecuentes en las instituciones educativas o en los seminarios de formación religiosa, se convertían en tema de interés público.

La pederastia siempre está inscrita en un tejido de relaciones que no está desvinculado de su malla jerárquica y disciplinaria. Supone una relación de dominación sobre la víctima que va más allá de su componente sexual explícito, la cual es reforzada por los signos culturales de la edad y la condición de figura de autoridad (maestro, sacerdote) que ostenta el victimario. El pederasta eclesial se ampara muchas veces en su triple condición de autoridad religiosa, moral y docente. Pureza y mácula en la retórica intraeclesial tienden a yuxtaponerse a la relación entre el sacerdote pederasta y su víctima o víctimas. A la sexualidad pederasta que inflige daño al menor en estado de indefensión, se suma el daño crónico que ejerce el sacerdote pederasta revestido de poder, sobre la subjetividad de su víctima, a través de la de la culpa, el temor, y la vergüenza del honor mancillado.

En 2012 los Legionarios de Cristo se suman en una nueva crisis moral internacional, al darse a conocer que la pederastia no había desaparecido con la separación 
y deceso de su fundador en 2008. El Vaticano ha hecho público el procesamiento de siete de sus integrantes por el mismo crimen, pero silencia que sus víctimas, usualmente adolescentes y jóvenes no serán objeto de reparación alguna. No se les pedirá perdón y menos se les ofrecerá cubrir los gastos de su atención psicológica o una indemnización económica, seguirán la misma práctica del arrepentimiento simulado con avaricia. Los Legionarios persisten celosamente en maquillar su imagen pública, a costa de sacrificar un bien común pero ajeno: el de las víctimas. Otra manera de configurar los muy de moda "daños colaterales".

En 2012, la red internacional de empresas educativas bajo su característico sello legionario de "Cumbres", ha perdido credibilidad ante los padres de familia y la ciudadanía de muchos países del mundo, pero no tanta como para desarmar su posicionamiento en las estructuras de poder. ¿Por qué estos crímenes deben ser juzgados únicamente bajo los parámetros lábiles del derecho canónico y no de los fueros judiciales y los códigos penales que tipifican tales delitos y prescriben particulares sanciones? El celo canónico frente a las herejías se vuelve condescendiente frente a los "pecados de la carne" y los daños y agravios diversos con los que fueron marcadas sus pequeñas e indefensas víctimas.

Lo deseable y lo posible sería que ambos procesos no se contrapongan. La inercia, si es que no culpabilidad, del poder fáctico de los legionarios prefiere el "borrón y cuenta nueva" y el silencio.

\section{Los orígenes: Maciel y el gobierno conservador}

México vivía los inicios de un giro político e ideológico hacia la derecha, concluido el mandato de Lázaro Cárdenas e iniciado el gobierno de Manuel Ávila Camacho. El contexto internacional estaba signado por la exitosa ofensiva desplegada por Alemania, Italia y Japón durante los inicios de la Segunda Guerra Mundial, también los favorecía. Ezequiel Padilla, figura reaccionaria cercana a la red liderada por Portes Gil, hacía malabares coqueteando con los Estados Unidos y permitiendo la restauración de relaciones comerciales con la España gobernada por el dictador Francisco Franco.

Bajo el paraguas protector del nuevo gobierno y su proyecto reaccionario de "unidad nacional", algunas corrientes conservadoras encontraron clima propicio para la realización de sus actividades. En su primera entrevista periodística tras haber ganado las elecciones declaró: "soy católico" aunque como hizo constar el propio entrevistador, la frase fue cambiada por la de "soy creyente" (Valadés, 2002, p. 242). Se alineó con los gobiernos autoritarios de América Latina con la finalidad de "cimentar en nuestro continente una política internacional cristiana, más justa y más noble" (Aspe Armella, 2008, p. 196).

El arzobispo Luis María Martínez atendió el guiño que le hizo a la Iglesia católica el presidente Ávila Camacho, al declarar que a éste lo consideraba sincero por lo que convocó a todos los católicos mexicanos a cooperar "verdadera y eficazmente" con el gobierno (Campbell, 1976, p.151). Este nuevo camino hacia la cooperación católica 
con el gobierno no fue bien visto por algunos sectores que integraban la variopinta red de organizaciones cristeras. Los disensos, tensiones, fracturas y reacomodos fueron inevitables. El joven Maciel se ubicó en la línea colaboracionista con el gobierno, aunque sus ideas abrevaron en la "Legión", entidad de jóvenes católicos, que clandestinamente se organizaron y expandieron por todo el país. (Hernández García de León, 2004, p. 43) Muchos de ellos convergieron en el curso de una década con la Unión Nacional Sinarquista, Maciel optó por una vía heterodoxa, la de auspiciar una nueva legión vinculada a un proyecto misional.

Maciel evocando o fabulando su mística inspiración misional dijo que fue: "la moción del Espíritu Santo para fundar la Legión de Cristo, aquel viernes primero, fiesta del Sagrado Corazón, de 1936", la que lo llevó a la constitución de los legionarios un 3 de enero de 1941. En realidad este presunto acto fundacional en la memoria e imaginario de los Legionarios de Cristo, es una tradición inventada, un mito de los orígenes. En los hechos, Maciel, bajo la guía de Francisco González Arias, Obispo de Cuernavaca, inauguró una extensión de su Seminario en Tlalpan, Ciudad de México, en la que se inscribieron 13 niños entre 9 y 14 años (Aristegui, 2010, p. 292).

Tiene razón Bernardo Barranco al vincular la constitución de los Legionarios de Cristo con el periodo en el cual el México posrevolucionario vivía en "ese sueño de modernización de la sociedad mexicana caracterizado por una gran corrupción, que es también la que refleja Maciel" (Aristegui, 2010, p. 93). El nuevo clima ideológico y moral condicionado por el curso de la II Guerra Mundial y las tradiciones de la corrupta burocracia y clase política mexicana afectaron a las organizaciones católicas que más habían combatido al estado posrevolucionario. En la nueva coyuntura el alto clero no veía con buenos ojos que continuase el liderazgo beligerante de Salvador Abascal en La Unión Nacional Sinarquista.

El dirigente sinarquista Antonio Santacruz, que había mantenido una relación muy cercana con el arzobispo Martínez fue de similar parecer y es posible que preparasen el camino para el relevo de Abascal, no sin antes persuadirlo de llevar adelante un proyecto de colonización en Baja California Sur con implicaciones religiosas y de carácter geopolítico, con la finalidad de frenar el posible intento norteamericano de ocupar la península bajo el pretexto de que el curso de la Segunda Guerra Mundial ponía en peligro las costas del Pacífico de las Américas. La frontera del catolicismo y de la hispanidad sería defendida por los colonos sinarquistas. Abascal se reunió con Ávila Camacho para hablar de dicho plan, lo que refrenda que tenía cifradas algunas expectativas en el presidente, aun cuando las ayudas prometidas nunca llegaron (Aristegui, 2010, p. 154).

El liderazgo de la organización sinarquista había pasado a manos de Manuel Torres Bueno el 13 de diciembre de 1941. La tendencia ideológica dominante en las filas sinarquistas se iba inclinando a favor de una alianza de México con los Estados Unidos y de una mayor colaboración con el gobierno. Entre el panamericanismo religioso remozado con la colaboración del obispo Fulton J. Sheen -figura visible del clero estadounidense- y el hispanismo ultramontano de los sinarquistas tradicionales no había posibilidades de convergencia, menos de acuerdo, independientemente de 
que Torres Bueno sostuviese lo contrario (Aristegui, 2010, p. 157-159). El cisma sinarquista se hizo inevitable.

Un periodista ha evocado un chiste político de la época: En tiempos del presidente Manuel Ávila Camacho (1940-46), "corría el chiste de que al primer mandatario lo manejaba una poderosísima organización religiosa: la SOAC. Eran las iniciales de su esposa, Soledad Orozco de Ávila Camacho, fervorosa creyente de quien se decía que era el poder tras el trono en materia religiosa y gracias a ella se comenzó a permitir al alto clero saltarse las leyes que limitaban su actividad política" (Morales, s/f). Era una exageración, la pareja presidencial compartía las mismas creencias, aunque los gestos aguerridos de la primera dama fueron tan públicos y notorios que dieron pie a más de un chiste político. Otro hecho, refrenda este aserto. Doña Soledad, contrariando el gusto de su marido que había auspiciado la culminación e inauguración de la escultura de la Diana Cazadora, en la glorieta más próxima al bosque de Chapultepec, decidió ponerle calzones de bronce. La Diana, inaugurada el 10 de octubre de 1942, muy pronto perdió calidad estética durante la temporada sexenal. Los calzones quedaron como un horrendo pegoste (Hernández Sotelo, 2004, p.15).

Las declaraciones del presidente preanunciaron algo más que un régimen de coexistencia, según lo refrenda el acuerdo de cooperación suscrito con el Arzobispado (Hernández García de León, 2004, p.199). Ávila Camacho hizo explícita su decisión de dar por concluido bajo su mandato el proceso de secularización del país, dando juego al clero y a las órdenes religiosas. Dio por finalizado el exilio de 17 años del obispo José de Jesús Manrique y Zárate, tenaz enemigo de los ideales laicos de la Revolución mexicana y partidario de la guerra cristera (Mutolo, 2005). Fue certero el juicio de Silva Herzog al escribir que: “...en el decurso del sexenio el clero recobró las trincheras perdidas durante la Revolución y los gobiernos revolucionarios. A partir de entonces se multiplicaron las escuelas confesionales y comenzó a violarse el artículo $3^{\circ}$ constitucional" (Silva Herzog, 1994, p.267).

Maciel, conocedor de que los nuevos tiempos le eran favorables fundó un 3 de enero de 1941 en la capital mexicana, la unidad pionera de los Legionarios de Cristo bajo la denominación Escuela Apostólica Misional del Sagrado Corazón de Jesús. La permisividad de Ávila Camacho con Maciel no fue excepcional; su apuesta era clara: deseaba ganar al clero católico y de paso a su feligresía. Compartía ideológicamente con el alto clero los valores de unidad, orden y paz social. En 1945 autorizó que la iglesia ingresase de manera abierta a los espacios públicos bajo el pretexto de la coronación de la Virgen de Guadalupe, a la cual le permitió algo más: una transmisión radial en cadena nacional abiertamente confesional (Ai Camp, 1998, p.48).

En 1942 Octaviano Véjar Vásquez (1900-1974), titular de la SEP, inició una agresiva campaña antisocialista y anticomunista (Lerner, 1979, p. 122) y favoreció a los proyectos educativos de las órdenes religiosas que durante el callismo y el cardenismo habían funcionado bajo disfraces laicos. Véjar expulsó de la SEP a todo integrante que abogase por la educación socialista o posiciones anticlericales. Proponía una imaginaria escuela de amor, afirmando que nada "vale un ideal de redención si no se dibuja tras él la silueta de la cruz" (Hernández García de León, 2004, p.201). 
Prohibió la coeducación en aras de arcaizar las relaciones de género bajo los moldes más tradicionales del patriarcalismo.

Durante este periodo, Marcial Maciel logró proveerse de ingentes y periódicas donaciones económicas de parte de doña Flora Barragán de Garza, destinadas para su uso personal y para la infraestructura y proyección de los Legionarios de Cristo a través de la inversión en el Instituto Cumbres, y la adquisición de terrenos en Irlanda (Aristegui, 2010,pp. 139 y ss.).

\section{Un mafioso con sotana en Cuernavaca}

Gregorio Araiza quien frecuentaba periódicamente el Vaticano a partir de diciembre de $1934,{ }^{1}$ fue quién diez años más tarde desde ese mismo lugar, remitiese un telegrama urgente al arzobispo primado de México para que siguiendo la cadena de mando eclesial Francisco González Arias, obispo de Cuernavaca y tío de Maciel lo ungiese a la brevedad como sacerdote. ${ }^{2}$ Previamente, Maciel había logrado ser recibido por Pío XII en el Vaticano y ello había inclinado la balanza a su favor (Torres, 2001, p.21).Si a partir de 1944 Maciel supo ubicarse en la lógica cultural de los favores a través de las cadenas de mando eclesial para su propio beneficio, en 1948 mercantilizó con cierto éxito la transversalidad de sus redes.

En 1948 los informes procedentes de Cuernavaca, ciudad de México y de Comillas en España, documentaban que Maciel torturaba psicológicamente a los novicios y becarios, así como que había falsificado una carta del Cardenal Spellman en la que presuntamente le comunicaba que el Vaticano le había conferido a su entidad el nihil obstat y de la cual presumía ${ }^{3}$, mientras que por otro lado sobornaba con 12 mil dólares a una autoridad eclesiástica para que le consiguiese en el Vaticano la soñada autorización para consolidar su proyecto institucional. ${ }^{4} \mathrm{El} 23$ de septiembre Maciel en complicidad con el H. Alfredo de su congregación y dos matones contratados, montó un "atentado comunista" contra su vida que fue desenmascarado por dos religiosos testigos del evento y comunicado por escrito a Monseñor Alfonso Espino, obispo de Cuernavaca. La intención de Maciel fue pasar a la condición de víctima y ganar solidaridades en los mandos eclesiales que neutralizasen o distrajesen de la atención de las denuncias hechas contra él por los jesuitas. ${ }^{5}$ Maciel en su alucinado proyecto de victimizarse para sacar ventaja en las jerarquías eclesiales, no podía apelar a los excesos de la guerra cristera, pero sí a su delirante visión sobre la conspiración comunista, a un año de declarada la guerra fría, visión que cayó por incoherente en saco roto.

\section{Bajo el paraguas del conservadurismo autoritario}

Si el gobierno de Ávila Camacho les dio a los Legionarios de Cristo su primer espaldarazo, otros gobiernos de derecha como los de Miguel Alemán (1946-1952), Ruiz Cortines (1952-1958) y López Mateos (1958-1964), le permitirían extender sus redes y proyectos, aún durante el trienio de 1957 a 1959 en que Maciel vivió su tibia suspensión en tierras europeas. Fue el gobierno fascista de Francisco Franco quien le abrió un puente no sólo con España sino con la propia Europa. 
Las buenas relaciones de los Legionarios con el Presidente López Mateos han sido testimoniadas por Miguel Ángel Díaz Rivera, uno de los defensores vergonzantes de Maciel cuando evoca: “... acompañé a López Mateos en el año 66. Fue a Europa al frente del Comité que preparaba los juegos olímpicos. Fui su guía en la ciudad. Lloró cuando vio la imagen de la Guadalupe en la Basílica de Roma y me dijo: 'yo no soy un católico vergonzante'. Cuando nos despedimos me dijo: 'Padre, regrese a México. Si quiere lo hago Director de la Pinacoteca de San Diego' (Aristegui, 2010, p. 133). No fue el único testimonio que narra la estrecha relación de López Mateos con los legionarios. El escritor José Ituriaga refiere una conversación amical compartida en círculo cerrado con Marcial Maciel, Benito Coquet y Ruiz Cortines en 1968, cuando el último ya había abandonado la presidencia (Iturriaga, 2003, p. 414). Recordemos el contexto político en que Maciel fue suspendido, cubre los dos últimos años del gobierno de Ruiz Cortines, y el deceso de Pío XII, y el primero de López Mateos, bajo el cual pudo reposicionarse reintegrándose a la jefatura de los Legionarios de Cristo. Bajo el mandato de Ruiz Cortines, no obstante su filiación católica, las relaciones entre la iglesia y el estado se friccionaron. El gobierno trató de frenar los intentos de las organizaciones (católicas) laicas como la Acción Católica y la Unión Nacional de Padres de Familia, que pretendía alcanzar mayor injerencia en la educación pública, y en la censura cinematográfica y de espectáculos (Torre, 2006, p. 59). La sanción y separación de Maciel careció de un ambiente favorable; el puritanismo moral de la acción católica y otras entidades afines habían asumido ribetes de intolerancia. Gracias a su presión, y a la propia voluntad gubernamental, se cerraron muchos prostíbulos y se acrecentó la censura sobre los espectáculos: carpas, teatros y cines. Maciel era una figura incómoda y fue invisibilizada en México gracias a su estancia en Europa.

Bajo el gobierno de Aznar y con el respaldo del Partido Popular, los Legionarios de Cristo escalaron posiciones estratégicas al incrustar a uno de sus cuadros en el equipo de asesores sobre la educación pública. Las hermanas Ana y Macarena Botella son activas colaboradoras de los Legionarios. No son los únicos, también se sumaron Francisco Álvarez-Cascos, Marcelino Oreja Aguirre ${ }^{6}$ y José Pedro Pérez Llorca. $^{7}$

\section{Cuernavaca: Lemercier y Méndez Arceo desenmascaran a Maciel}

En agosto de 1956, Sergio Méndez Arceo, obispo de Cuernavaca, Miguel Darío Miranda, arzobispo primado de México, Gregorio Lemercier, titular de la orden de los benedictinos con sede en Cuernavaca, presentaron las denuncias contra Maciel con fundadas pruebas sobre su pederastia clerical y su adicción a las drogas del género de los opioides sintéticos (Aristegui, 2010, p. 20) bajo la presentación de inyecciones de uso restringido y medicado: demerol y dolantina fabricadas por los laboratorios Abbot y Kern Pharma, respectivamente. En sus diversas presentaciones:

El opio cumple sus promesas y produce un goce absoluto. El único inconveniente es que la satisfacción extrema que procuran los opiáceos revela ser inestable, cada vez 
más difícil de alcanzar y finalmente inaccesible, pese al in crescendo de las dosis. Surgen así las células sedientas, el mono, el "nunca bastante" de los que nos hablan los adictos. (Sissa, 1997:196).

La adicción de Maciel ingresó en una espiral sin control. Lo que llama la atención es la manera en que los Legionarios procesaban simbólicamente la trama ritualizada del dolor y el consumo de la droga:

[a los] religiosos que le atienden en sus enfermedades les ha hecho creer que su enfermedad es una cosa extraordinaria y que, por lo tanto, necesita remedios extraordinarios para mitigar sus dolencias.

El Hno. Saúl Barrales que en aquellos días atendió en ocasiones al P. Maciel me dijo que hubo fechas en que calcula que se le administraron hasta cuarenta inyecciones en un mismo día. ${ }^{8}$

El consumo de opiáceas sirvió de acicate de la entusiasmada retórica salvacionista y mesiánica del fundador de los Legionarios:

Lo más serio es el espíritu de trampa constante, la vida de absoluto desorden del P. Maciel, su tratamiento personal reñido con la ascética que sabemos y las interrogantes. ¿No será la morfina la que le da una inspiración "misticoide” para hablar luego a los suyos? ¿Por qué todos los comillenses, o casi todos, y exjesuitas, coincidimos en la apreciación y hemos tenido el "desengaño"??

Los testimonios de las víctimas mencionan que Maciel muchas veces sumó al placer de las opiáceas el de la sexualidad coercitiva (estimulación erógena, masturbación y sexo anal), recordándonos que la "naturaleza del deseo es insaciable" (Sissa, 1997: 14). Maciel ha sido caracterizado como un psicópata, pero eso nos ayuda poco en la explicación de la trama cultural en la que se inscribe su pederastia. Un testimonio da cuenta de la relación entre el dolor y la seducción pederasta:

... en cierta ocasión dicho hermano [Andrés García Vega] me manifestó que el P. Maciel le había engañado, induciéndole a hacerle tocamientos, porque decía el P. Maciel que ese contacto con el cuerpo humano le proporcionaba la polución que necesitaba para poder descansar y así se le mitigaban sus dolencias. ${ }^{10}$

Subrayamos el hecho de que el caso Maciel, ilustra como el placer plural, móvil y renovable deviene en tolerancia y dependencia, es decir en drogadicción y pederastia insertas en redes y prácticas culturales de poder y subordinación. "El placer del mal" de la toxicomanía descansa en deseo insaciable, en un temor al sufrimiento de la carencia de los estimulantes del placer, que orienta el comportamiento autoritario frente a sus subordinados o víctimas. El ejercicio del poder del pederasta eclesial y sus cómplices, convierte el daño en sus víctimas, en acto religioso purificador.

En el caso de Maciel el dolor constituye un eje discursivo central que compite con el amor a los niños. La conocida frase de Cristo: "dejad que los niños vengan a mí" fue reapropiada por Maciel al igual que otros curas pederastas. El dolor le permitió al fundador de los Legionarios de Cristo justificar sus prácticas de pederastia: 
... uno de los chicos pertenecientes a la Escuela Apostólica de la que ya desde entonces era yo rector, vino a decirme en el año de 1950 lo que le hiciera el P. Maciel -que le curara la polución - y entonces yo le hablé al P. Maciel duramente, diciéndole que me separaba porque no estaba dispuesto a seguir colaborando en esa forma [...] me suplicó que no me fuera: que él no se daba cuenta de lo que hacia cuando estaba enfermo, pues eran muy fuertes sus dolores, que sin duda lo que había hecho con ese niño había sido en estado de inconsciencia. ${ }^{11}$

Se trataba de un dolor real o imaginario asociado a su adicción a las opiacéas sintéticas. Dolor intermitente y multiforme no suficientemente esclarecido: ¿Migraña? ¿Dolor generado por la misma adicción frente a la ausencia de la droga? ¿Simulación del dolor? Dolor consentido y mitigado, dolor transformista, dolor contaminante que se proyecta sobre el cuerpo de sus víctimas.

El dolor como categoría polisémica situada en el imaginario eclesial, asume densa carga teológica, vinculándolo a la culpa, el castigo y la purificación. En este horizonte de sentido debemos subrayar el carácter relacional del dolor. Une a la persona doliente con lo sagrado pero también con las personas con las cuales lo comparte, en términos horizontales o verticales. El dolor del pederasta Maciel es vertical con respecto a sus jóvenes víctimas confiriéndole, por añadidura, un sentido de crueldad, aunque también, al desvincularlo de la mácula, lo "sacraliza". Estas figuras del dolor representan una:

..."punción de lo sacro", porque arranca al hombre de sí mismo y lo enfrenta a sus límites, pero se trata de una forma caprichosa, que hiere con inaudita crueldad. Sin embargo, si permanece bajo el control moral o si es superado, ensancha la mirada del hombre, le recuerda el precio de la existencia, el sabor del instante que pasa (Le Breton, 1999, p. 18).

La opiácea como sustancia alteradora de la conciencia y de los sentidos se proyecta en función del "placer narcótico" el cual es "fascinante porque es doblemente negativo: más allá de la supresión del dolor físico, es sosiego para el dolor de vivir. Toda droga es paradójicamente, anestésica” (Sissa, 1997: 16).

En los testimonios y pruebas contra la adicción de Maciel que fueron documentados de manera recurrente al Vaticano desde 1948, aparecen involucrados los jóvenes seminaristas, las monjas adscritas a unidades hospitalarias y otras personas de dudosa ocupación. El uso de sustancias sintéticas alteradoras de la conciencia ha venido ganando terreno en los ampliados mercados transnacionales que nutre la industria química farmacéutica y los laboratorios ilegales subordinados a la economía subterránea o negra. Lo grave en este caso fue la red de complicidad y proveedores que tejió Maciel en los marcos eclesiales. En otras palabras, la adicción personal, en la medida en que comprometía a otras personas en su calidad de víctimas o cómplices planteó un problema triple: de salud, de moral y de criminalidad.

¿Cuáles eran las drogas usadas por Maciel? Fueron las de uso médicos restringidos como la dolantina también fabricada por el laboratorio Bayer. Gregorio Lemercier 
sacerdote benedictino de nacionalidad belga -introductor del psicoanálisis en los monasterios benedictinos del país, fundador del Centro Psicoanalítico Emaús e integrante del Centro Intercultural de Documentación (Cidoc) fundado por Iván Illich en Cuernavaca, se percató de las desviaciones de Maciel y se lo comunicó a Sergio Méndez Arceo, obispo de Cuernavaca. Lemercier contaba con información seria acerca de las perversiones que se venían dando en el seno de los Legionarios de Cristo por mediación activa de su fundador, Maciel. En 1956 Méndez Arceo le remitió un informe al Monseñor Arcadio Larraona denunciando a Maciel por el uso de "... procedimientos tortuosos y mentirosos; uso de drogas heroicas; actos de sodomía con chicos de la congregación... Yo suplico pues a V.R. que esta carta solo sirva a V.R. para estar informado y con más cautela que antes..." ${ }^{12}$ Por esas mismas fechas, el P. Carlos de la Isla denunció a Maciel por '... tactos impúdicos'... "estos hechos... llegaron a conocimiento de... González Arias, Obispo entonces de Cuernavaca..."13

Los primeros visitadores del Vaticano para investigar a Maciel recogieron variados testimonios de denuncia, entre ellos el de Luis Ferreira, a pesar de las cortapisas que supo ponerles el acusado. Las denuncias cruzaban información sobre la conducta perversa de Maciel tanto en Cuernavaca como en Europa. Luis Ferreira brinda su testimonio de lo acaecido en Roma en que los legionarios le rogaban “...encarecidamente que no me viniera de Europa sin traerme al padre Maciel, porque su estancia en la casa de Roma era un positivo escándalo, pues a tal grado habían llegado las cosas que habían tenido que quitar las llantas a los coches y esconder las llaves de encendido, porque el padre Maciel mandaba a determinados religiosos por santa obediencia a que fueran a conseguirle las inyecciones y cuando se negaban él mismo iba [...] optamos por internarlo en un sanatorio, pero como se negaron a proporcionarle las inyecciones que pedía, se escapó de él y se fue a otro que le convenía". ${ }^{14}$

Todo indica que Larraona, quien tenía a su cargo la investigación ordenada por el Vaticano encubrió a Maciel. La separación de Maciel de la congregación por orden del Vaticano entre 1957 y 1959 fue una medida en cierto sentido conciliatoria, para proteger a Maciel frente a la gravedad de los cargos, y por otro lado, separarlo del foco y escenario de conflictos y agravios (Torres, 2001, p.309). Maciel, el fundador de la orden Legionarios de Cristo y de la denominación laica Regnum Christi, dista de ser un caso aislado de transgresiones a la moral pública y la legalidad, el cual fue protegido tanto por el Vaticano como por los gobiernos panistas. Recordarán los lectores que el fallo papal del 19 de mayo de 2006 no condenó a Maciel a pesar de las evidencias en su contra; únicamente lo invitó a asumir "una vida reservada de oración y de penitencia, renunciando a todo ministerio público". Ratzinger, en ese entonces, Prefecto de la Congregación para la Doctrina de la Fe, faltó a la verdad cuando sostuvo que las denuncias contra Maciel recibidas en el Vaticano comenzaron a llegar a partir de 1998, como lo demuestran los testimonios y actas recogidos por los visitadores papales Anastasio Ballestero, Prepósito General de los Carmelitas descalzos y Benjamín Lachaert, Vicario General Carmelita, que en 1956 investigaron a Maciel y que en febrero de 1957 presentaron un detallado informe de denuncia de hechos. ${ }^{15}$ 
A tres años de ser reinstalado Maciel al frente de los Legionarios, gracias a los favores de algunos dignatarios de la cúpula del Vaticano, fue motivo de una nueva denuncia. El informe del vicepresidente del Colegio Farmacéutico sobre Maciel en 1962 abrió dos líneas sobre el tráfico y consumo de opiáceas sintéticas entre los Legionarios de Cristo. La primera fue sustentada en el propio testimonio de Maciel, quien declaró: “[...] que él no se hacía responsable de los falseamientos de nombres, y de la petición de recetas que habían efectuado los otros "seminaristas." 16 Maciel no negó su consumo pero deslizó la idea de que existían otros consumidores de opiáceas entre los Legionarios de Cristo. Los adictos se valen de todo tipo artilugios para satisfacer ese "placer del mal" que cada vez se vuelve más efímero e insaciable. Manuel Castro, el dirigente farmacéutico, aportó con detalle el modo en que Maciel rompió toda norma ética y legal para hacerse de las opiáceas en España. ${ }^{17}$

\section{Un poder fáctico transnacional}

La figura paradigmática de los Legionarios de Cristo y de la Regnum Christi sigue gravitando en su seno gracias a la poderosa red que tejió y que sigue activa en sus jerarquías, en la política y en el manejo de los ingentes recursos económicos que poseen. El hecho de que Maciel no fuese juzgado por los crímenes que cometió, prueba la fuerza de la red macielista. Para los actuales directivos de dichas entidades, Maciel cometió "errores", forma retórica de solapar lo que realmente hizo en agravio de muchos menores que cayeron presas de su poder y fueron objeto de agravios sexuales. Para los legionarios, el libro que pirateó Maciel sigue siendo libro de cabecera, lo que pone bajo cuerda su respeto a la propiedad intelectual.

El Regnum Christi, brazo seglar de los Legionarios de Cristo, según su página oficial, afirma contar en sus filas con "cerca de 70.000 miembros, jóvenes y adultos, diáconos y sacerdotes, en más de 30 países" ${ }^{18}$ y Noviciados en: Cornwall (Canadá); Cheshire (Estados Unidos); Monterrey (México); Caracas (Venezuela); São Paulo (Brasil); Salamanca (España); BadMünstereifel (Alemania) y Gozzano (Italia). Se trata de una transnacional de la fe especializada en ganar la adhesión y parte de los recursos de las élites empresariales, así como favores políticos especiales, fuera de los negocios educativos que son altamente rentables y exonerados de régimen fiscal. Coincidimos con la caracterización que hizo de esta entidad religiosa Carmen Aristegui en 2010 apoyándose en Jason Berry (1997) cuando afirma que se trata de una: "especie de holding eclesiástico empresarial. Con 15 universidades, 177 colegios, casi 150,000 alumnos y miles de empleados, esta organización genera cantidades millonarias que ahora el Vaticano está decidido a identificar, y veremos si también a administrar" (Aristegui, 2010,p. 26).

Había corrido año y medio de la nueva documentación sobre los crímenes de Maciel que había recibido el Vaticano, cuando Ratzinger le escribió al acusado el 19 de febrero del 2000: "Le estoy sinceramente agradecido. También quisiera darle las gracias por las diversas ayudas que yo mismo he experimentado en estos últimos años".${ }^{19}$ ¿A qué ayudas se refiere Ratzinger? Obviamente a las tentadoras remesas que Maciel le remitía a Ratzinger y a otros dignatarios eclesiásticos en el Vaticano como el cardenal Ángelo Sodano; el secretario personal de Juan Pablo 
II, monseñor Stanislaw Dziwisz ${ }^{20}$ y Eduardo Martínez Somalo, prefecto de las Congregaciones Religiosas en esa época. Tenía razón Jason Berry, el connotado periodista norteamericano al definir a Maciel como "el hombre que compró a Roma”.

La política de tolerancia frente a la pederastia eclesial católica bajo los dos gobiernos panistas -Vicente Fox (2000-2006 y Felipe Calderón (2006-2012) -no parece llegar a su fin con el ascenso del PRI al poder y el inicio de una alternancia neoconservadora. En muchos otros países, los casos de pederastia documentados no quedarían en la impunidad, en México no ha sucedido lo mismo. La visita de Benedicto XVI a México, celebrada por el presidente Felipe Calderón, dejó fuera de agenda la atención a las víctimas de la pederastia de Maciel. La red que tejió no ha sido sujeta a investigación. Con mucho retraso la jerarquía de los Legionarios de Cristo decidió recién este año iniciar un proceso a siete de sus integrantes, ellos fungirán como los chivos expiatorios, ocultando una red mucho más amplia y que sigue operando dentro y fuera del país. Federico Lombardi, el jesuita vocero del Vaticano, dice no entender el "revuelo mediático" suscitado por el conocimiento de estos siete casos de pederastia y tratar de maquillar de pureza y probidad a la nueva jerarquía de los Legionarios. ${ }^{21}$ El poder en algunas culturas tradicionales toma posesión simbólica de la "pureza física" y de la "pureza moral" y precisa los límites del peligro y del tabú (Balandier, 2004, p. 136). No es diferente el manejo que hace el poder eclesial de la asunción de la pureza y el pecado que la contamina. La restauración simbólica del equilibrio o purificación recurre más a las imágenes sagradas patriarcales que a las marianas. La retórica, el ritual de purificación de los pecados y los símbolos que le corresponden siguen una cadena jerárquica que da juego a la trasgresión pederasta y al mismo tiempo al exorcismo del mal y del pecado. La virilidad pederasta identifica a la pureza por su marcado acento femenino sin llegar a ser exclusivamente mariano en el cuerpo de su víctima. La crueldad y el daño pierden visibilidad en el agresor y en la cúpula eclesial. Lo cierto es que Maciel, los otros pederastas y traficantes de drogas han sembrado la más temida amenaza católica: el mal en sus diversas aristas. Los negocios de los Legionarios han solventado sus redes de poder y complicidad.

Una orden como los Legionarios de Cristo que maneja un importante complejo educativo que abarca todos los niveles formativos en México, merecería ser investigada. John O' Reilly, el fundador de los Legionarios de Cristo en Chile, ha sido denunciado recientemente por abuso sexual de una estudiante menor de edad en el Colegio Cumbres..$^{22}$ La petición de las exnovicias al Papa para que clausure la escuela de los Legionarios de Cristo en Rhode Island por los agravios múltiples que padecieron en ella y que persisten para desdicha de algunos que continúan estudiando en ella, quizás no prospere. ${ }^{23}$ Los recursos económicos que aportan los Legionarios de Cristo al Vaticano son muy importantes y provienen principalmente de su emporio educativo transnacional.

Trato especial a quien fuese amigo personal de Juan Pablo II y "el recolector de fondos más exitoso para la iglesia católica en el siglo XX” (Franco, 2008, p.138). 
Incidió a favor de ello, el apoyo que recibió Maciel de Ángelo Sedano, el influyente cardenal italiano, de triste memoria para los latinoamericanos por haber abogado a favor de la libertad de Augusto Pinochet, su amigo, ante el gobierno británico en 1999. Maciel formaba parte de una red de la derecha internacional, tanto eclesial como política. Alfonso López Trujillo y Darío Castrillón Hoyos, los cardenales colombianos formaban parte de ella dentro y fuera del Vaticano, así como de Cipriani, -el cardenal peruano- todos ellos insertos en el manejo de los recursos económicos del Vaticano y en el solapamiento de los Legionarios y sus crímenes.

\section{A manera de conclusión}

La pederastia eclesial ha suscitado abordamientos diversos por las más diversas disciplinas científicas y humanísticas a partir de la segunda mitad del siglo XIX al presente. Nuestro artículo, desde una perspectiva interdisciplinaria, ha demostrado que la pederastia eclesial, más allá del caso Maciel, se inscribe comúnmente en redes de poder. La fetichización de la virilidad pederasta es ambivalente, se exculpa a través de artilugios religiosos, al mismo tiempo que se solaza en el ejercicio cruel de la violencia sexual y simbólica contra sus víctimas. La fetichización de la virilidad pederasta pone en tela de juicio el mito eclesial de celibato, más que voto es una promesa prescindible.

La fetichización de la virilidad de la pederastía eclesial queda resumida de manera ejemplar en el diario íntimo del sacerdote brasileño Tarcisio Sprícigo, el cual registró sus experiencias, reflexiones, recomendaciones y reglas de seducción y sometimiento de los menores de edad. Frente a los jueces civiles que lo juzgaron sostuvo: "después de mi debilidad en el campo sexual, aprendí una lección. Y éste es mi solemne descubrimiento: ¡Dios perdona siempre, pero la sociedad nunca!”24

Muy pronto los cinéfilos latinoamericanos podrán ver la cinta Obediencia perfecta dirigida por el cineasta mexicano Luis Urquiza y que versa sobre el caso de Marcial Maciel y los Legionarios de Cristo. Alberto Athié, una de sus reales víctimas que renunció al sacerdocio y documentó la denuncia de hechos ante la curia del Vaticano, realizó un incisivo comentario a la agencia de noticias AFP sobre dicha película: "No es sólo el caso de un individuo, existen otros que aprovechando su investidura han cometido abusos (...) y es también cuestión de un comportamiento institucional de encubrimiento de estos abusos, y esto queda claro en la película" ${ }^{25}$

En el Perú la pederastía eclesial sigue siendo un tema espinoso para los integrantes de la cúpula de la jerarquía católica, su silencio o modo evasivo de tratar los más recientes casos de los sacerdotes pederastas Taylor Benson, Jef Van Den Ouweland y Waldir Pérez Salinas, son un botón de muestra.

Como hemos podido apreciar Los Legionarios de Cristo -congregación católica romana- y la asociación seglar Regnum Christi encontraron un ambiente propicio para su desarrollo en México y posteriormente en otros países, como hemos podido contextualizar y explicar a grandes trazos, subrayando las facilidades de los gobiernos en turno, priistas y panistas. Hemos particularizado la presencia de los 
Legionarios en la ciudad de Cuernavaca en sus orígenes y desarrollo. Dejamos para otra oportunidad el análisis de los Legionarios pos-Maciel, aunque adelantamos la existencia de líneas de continuidad con la política de su fundador, más allá de sus maquillados giros de rectificación.

Los medios siguen colocando en el primer plano a su fundador, el michoacano Marcial Maciel Degollado (1920-2008) declarado por el papa Juan Pablo II "guía eficaz de la juventud", mandado a retiro y oración por su sucesor Benedicto XVI, más por su probada pederastia que por la piratería intelectual que hizo del libro Salterio de mis horas (1941) de Luis Lucía Lucía, sacerdote republicano español y por su adicción a las opiáceas. Figura bajo sospecha como probable autor intelectual de dos homicidios, uno de ellos el del ex rector de la Universidad Anahuac (Aristegui, 2010, pp. 49-50). Lo que se obvia es que las acciones de Maciel no hubiesen podido realizarse en escenarios mexicanos, españoles, norteamericanos y aún del Vaticano si no hubiese contado con una doble red de complicidad dentro y fuera de los Legionarios de Cristo.

En esta red protectora de la pederastia eclesial, la responsabilidad de Juan Pablo II y Benedicto XVI en el tratamiento del tema debe ser diferenciada. Maciel arrastró a su red de complicidad a dos papas. Posiblemente no haya otro caso en la historia. La red tejida por Maciel siguió las líneas de jerarquía eclesial, política y empresarial. A la curia romana la ganó a través de sus regalos y de sus remesas de dinero. El silencio de Ratzinger en su momento frente a Juan Pablo II y frente al propio Maciel antes de sus respectivos decesos, se explica en el marco de la red.

La red mafiosa de Maciel se ocultó a la caída estrepitosa de su jefe y nada prueba que haya renunciado a ser reproductora de prácticas análogas, por lo que la ciudadanía debe estar alerta a sus movimientos dentro y fuera del país. Una orden como los Legionarios de Cristo que maneja un importante complejo educativo que abarca todos los niveles formativos en México y otros países y que hizo parte de su vocación de fe, capitalizar a su favor los dones de las élites de poder empresarial y político merecería ser investigada. Consideremos no solo los casos documentados en México, sino también los más recientes procedentes de Santiago de Chile, de Rodhe Island y de otros lugares. La Comisión investigadora de los Legionarios integrada por cinco obispos visitadores: Ricardo Watti Urquidi, obispo de Tepic (México); Charles J. Chaput, arzobispo de Denver (EE UU); Ricardo Ezzati Andrello, arzobispo de Concepción (Chile); Giuseppe Versaldi, obispo de Alejandría (Italia) y Ricardo Blázquez Pérez, obispo de Bilbao (España), ha motivado el inicio de un proceso canónico contra siete legionarios involucrados en prácticas pederastas. Todo sugiere que se trata de un acto de limpieza selectiva que cumpla por un lado una función disuasiva hacia los pederastas de dicha Legión exonerados o no detectados y por el otro, una búsqueda de recuperación de imagen mediática ante la opinión pública de que el Vaticano no se anda con medias tintas en su labor profiláctica. El castigo canónigo a los siete legionarios que resultará de sus respectivos procesos no garantiza que sea una medida eficaz de disuasión. Lo que habría que evaluar es el celo o tolerancia con que los visitadores cumplieron su función investigadora cuando se den a conocer los lugares de residencia de 
los indiciados ante el tribunal eclesial. Bastará cruzar dicha información con la división del trabajo que tuvieron los cinco obispos: Así, monseñor Ricardo Watti Urquidi, obispo de Tepic (México), inspeccionará México y Centroamérica, donde los legionarios tienen 44 casas con 250 sacerdotes y 120 religiosos. Monseñor Charles J. Chaput, arzobispo de Denver (EE UU), se encargará de Estados Unidos y Canadá, donde poseen 24 casas con 130 sacerdotes y 260 religiosos. Giuseppe Versaldi, obispo de Alessandria, estará presente en Italia, Israel, Filipinas y Corea del Sur, donde se registran 16 casas con 200 sacerdotes y 420 religiosos. Ricardo Ezzati Andrello, arzobispo de Concepción (Chile), viajará por Chile, Argentina, Colombia, Brasil y Venezuela, donde los Legionarios tienen 20 casas con 122 sacerdotes y 120 religiosos. Y, por último, monseñor Ricardo Blázquez Pérez, obispo de Bilbao (España), será el encargado de visitar los centros de la Legión en España, Francia, Alemania, Suiza, Irlanda, Holanda, Polonia, Austria y Hungría, donde tienen en su haber 20 casas con 105 sacerdotes y 160 religiosos.

La red mafiosa de los legionarios tiene una base material, los ingresos económicos que se han manejado con una contabilidad secreta y discrecional además de recurrir a su transferencia a paraísos fiscales como Islas Caimán (Aristegui, 2010, p. 117).

El de la iglesia no es un caso excepcional. Los cultores de liberalismo contemporáneo prueban su falta de coherencia ideológica, frente a los fueros corporativos existentes en la Iglesia. Los marcos normativos eclesiales prueban también que no son compatibles con los derechos humanos universales.

La apertura del Centro Universitario Francisco de Vitoria (Cutfi), propiedad de los Legionarios de Cristo, se hizo con el aval de la Universidad Complutense de Madrid, gracias a los buenos oficios del rector Gustavo Villapalos, a quien la UNAM le otorgó un doctorado honoris causa. Uno de los operadores de esta red interuniversitaria fue el extinto Jorge Carpizo.

\section{NOTA DE RECONOCIMIENTO}

Mi agradecimiento a la etnohistoriadora Perla Jaimes por facilitarme algunos valiosos documentos del expediente Marcial Maciel existentes en el Vaticano y subidos en la red, así como por la revisión del presente artículo. Agradezco la lectura crítica del borrador mi colega y amigo José Luis González Martínez, reconocido antropólogo por sus estudios acerca de la religiosidad popular en el Perú y en México.

\section{REFERENCIAS BIBLIOGRÁFICAS}

Ai Camp, Roderic. (1998). Cruce de espadas: política y religión en México, México: Siglo XXI Editores.

Amenós Vidal, José María; Carmen Martínez Ibáñez. (2007). Iglesia y pederastia. Una aproximación al derecho canónico y la ley de protección de menores. Un análisis crítico sobre los casos de abusos sexuales en las diócesis de EE.UU. Barcelona. Fundación Psicología y Cristianismo. 
Aristegui, Carmen. (2010). Marcial Maciel, Historia de un criminal, México: Grijalbo.

Aspe Armella, María Luisa. (2008). La formación social y política de los católicos mexicanos, México: Universidad Iberoamericana.

Balandier, Georges. (2005). Antropología política, Buenos Aires, Ediciones del Sol.

Campbell, Hug. (1976). La derecha radical en México, 1929-1949. México: SepSetentas 276.

Comienza la Visita Apostólica a la Legión de Cristo. (s/f). Recuperado el 4 de agosto de 2012 de: http://www.religionenlibertad.com/articulo_imprimir.asp?idarticulo $=2786$

Escándalo de pederastia en Legionarios de Cristo en Chile (2012, 25 de julio). 24 horas. Recuperado de: http://www.24-horas.mx/escandalo-de-pederastia-en-legionariosde-cristo-en-chile/

Ex novicias exigen al Vaticano cerrar programa escolar. (2012, 9 de julio). Nuklearnoticias. mx. Recuperado el 4 de agosto de 2012 de: http://nuklearnoticias.mx/mundo/exnovicias-exigen-al-vaticano-cerrar-programa-escolar/

Franco, Jorge. (2008). Educación y tecnología: solución radical, México: Siglo XXI.

Granados Chapa, Miguel Ángel, (2006, 23 de mayo), "Legionarios”, Reforma (México). Recuperado el 2 de septiembre de 2012, de http://www.sectas.org/marcial_ maciel_23mayo_3.asp

Hernández García de León, Héctor (2004). Historia política del sinarquismo, 1934-1944. México: Porrúa.

Hernández Sotelo, Anel, (2004). El espíritu decente y el pudor benevolente: Ensayo sobre la censura corporal en México en la década de 1940. Boletín ENAH, núm.4, pp. 11-16.

Iturriaga, José E. (2003). Los Estudios Culturales En México, México: Fondo de Cultura Económica.

Le Breton, David. (1999). Antropología del dolor. Barcelona, Seix Barral.

Lerner, Victoria. (1979, julio-septiembre), Historia de la Reforma Educativa 1933-1945. Historia mexicana, v. 29, N. ${ }^{\circ}$ (113), El Colegio de México, p. 91-132.

"Manual del cura pedófilo", Zócalo Saltillo (México), 29 de marzo de 2012

Morales, Juan José. (s/f). Una nueva SOAC en el gobierno. Por Esto. Recuperado el 2 de agosto de 2012, de http://www.poresto.net/ver_nota.php?zona=qroo\&idSeccio $\mathrm{n}=15 \&$ idTitulo $=169784$

Mutolo, Andrea. (2005 septiembre-diciembre). El episcopado mexicano durante el conflicto religioso en México. Cuicuilco, núm. 12, pp.117-136.

¿Qué es el Regnum Christi?, (s/f). Recuperado el 2 de agosto de 2012 de: http://www. regnumchristi.org/espanol/articulos/seccion.phtml?se $=359$

Revelan carta de Ratzinger a Maciel. (2010, 29 de noviembre). El Siglo de Torreón. Recuperado el 2 de agosto de 2012 de: http://www.elsiglodetorreon.com.mx/ noticia/579062.html 
Silva Herzog, Jesús. (1994). Una vida en la vida de México: Mis últimas andanzas, 19471972, México, Siglo Veintiuno Editores.

Sisa, Giulia (1997), El placer y el mal. Filosofía de la droga, Buenos Aires, Manantial.

Torre,Renée de la. (2006). La EcclesiaNostra: El catolicismo desde la perspectiva de los laicos: El Caso de Guadalajara, México: CIESAS.

Torres, Alfonso. (2001). La prodigiosa aventura de los Legionarios de Cristo, Madrid: Foca (Tres Cantos)

Valadés, José C. (2002). Entrevista con Manuel Ávila Camacho. En Flores Torres,Oscar (Ed.), Historiadores de México del siglo XX, (pp. 240-253) México: Editorial Trillas. www.lavoluntaddenosaber.com

\section{NOTAS}

1 Araiza fue recibido por el papa el $1^{\circ}$ de enero de 1935 en su calidad de superior de la orden de los josefinos de México. "Vida Religiosa", Vanguardia (Madrid) 2 de enero de 1935, p. 16.

2 Telegrama 790, Stato de la Cittá del Vaticano, 23/5/1944 al [Arzobispo]: "saludándolo respetuosamente suplico intercer concédase obispo Cuernavaca facultad conferir sacerdocio Marcial Maciel terminó tercer curso ...es urgentísima necesidad atienda sección seminario según preces dirigida secretaría estado agradeciendo servirse comunicar solución cable. Gregorio araiza pro notario apostolico. http://www.lavoluntaddenosaber.com/images/Doc1-23mayo1944.pdf

3 Informe del P. Lucio Rodrigo; sobre Maciel, 9 de junio de 1948. http://www.lavoluntaddenosaber.com/images/Doc419junio1948.pdf

4 Ibíd.

5 Informe al Obispo de Cuernavaca, Alfonso Espino, 7 de julio de 1948. http://www.lavoluntaddenosaber.com/images/Doc59-FS-7julio1948.pdf

6 Político y empresario español. Colaboró con la dictadura franquista en el Ministerio de Asuntos Exteriores y asumió la titularidad de dicho ministerio entre 1976 y 1980. Secretario General del Consejo de Europa de 1984 a 1989 y Comisario Europeo de Transportes y Energía de1994 a 1999.

7 Político y empresario vinculado a la Kuwait Petroleum, la compañía de aviación Iberia y a la Loewe, empresa de artículos de lujo.

8 Declaración de Luis Ferreira al Sr. Orozco Lomelí sobre el P. Maciel. 23 de agosto de 1956. http://lavoluntaddenosaber. com/images/Doc122-23agosto1956.pdf

9 Sabino Arnaiz, "Informe sobre los Legionarios de Cristo" y su fundador, P. Marcial Maciel", 1 de febrero de 1956.http:/l lavoluntaddenosaber.com/images/Doc117-J3-1febrero1956.pdf

10 Declaración de Luis Ferreira al Sr. Orozco Lomelí sobre el P. Maciel. 23 de agosto de 1956. http://lavoluntaddenosaber. com/images/Doc122-23agosto1956.pdf

11 Declaración de Luis Ferreira al Sr. Orozco Lomelí sobre el P. Maciel. 23 de agosto de 1956. http://lavoluntaddenosaber. com/images/Doc122-23agosto1956.pdf

12 Carta del Obispo de Cuernavaca, M. Arceo a M. Larraona, 14 de agosto de 1956. http://www.lavoluntaddenosaber.com/ images/Doc121-J5-14agosto1956.pdf

13 Declaraciones de Luis Ferreira a Orozco Lomelí sobre Maciel, 23 de agosto de 1956. http://www.lavoluntaddenosaber. com/images/Doc122-23agosto1956.pdf

14 íbid.

15 Informe de la visita apostólica realizada por Anastacio Ballestero, 11 de febrero de 1957, http://www.lavoluntaddenosaber. com/images/Doc139-K2-11feb1957.pdf

16 Declaración jurada del farmacéutico Manuel de Castro Pérez, vicepresidente del Colegio Oficial Farmacéutico, a la diócesis de San Sebastián, 18-23 de marzo de 1962. http://www.lavoluntaddenosaber.com/images/Doc170-18-23marzo1962.pdf

17 Ibíd. "El padre Maciel... Ilegó en un coche particular a San Sebastián el día 17 de marzo de 1962 llegando al hotel... con una expedición de niños pequeños... que ese mismo día solicitó a través de la dueña del hotel, si le podía conseguir de una farmacia conocida una caja de Dolantina ampollas... que esta misma operación la efectuaron en la farmacia de 